\title{
Synthetic derivatives of genistein, their properties and possible applications
}

\author{
Aleksandra Rusin ${ }^{\otimes}$, Zdzisław Krawczyk ${ }^{1,2}$, Grzegorz Grynkiewicz ${ }^{3}$, Agnieszka Gogler ${ }^{1}$, \\ Jadwiga Zawisza-Puchałka² and Wiesław Szeja² \\ 'Maria Skłodowska-Curie Memorial Cancer Center and Institute of Oncology, Gliwice Branch, Poland; ${ }^{2}$ Silesian University of Technology, Depart- \\ ment of Organic Chemistry, Bioorganic Chemistry and Biotechnology, Gliwice, Poland; ${ }^{3}$ Pharmaceutical Research Institute, Warszawa, Poland
}

Genistein, the principal isoflavone constituent of soybean, attracts much attention as a natural molecule with significant affinity towards targets of potential medicinal interest, but also as a food supplement or prospective chemopreventive agent. Since its physicochemical properties are considered suboptimal for drug development, much effort has been invested in designing its analogs and conjugates in hope to obtain compounds with improved efficacy and selectivity. The aim of this article is to summarize current knowledge about the properties of synthetic genistein derivatives and to discuss possible clinical application of selected novel compounds. Some basic information concerning chemical reactivity of genistein, relevant to the synthesis of its derivatives, is also presented.

Keywords: synthetic genistein derivatives, inhibition of cell proliferation, tyrosine kinases, selective estrogen receptor modulators, anticancer activity, antimicrobial activity

Received: 03 November, 2009; revised: 09 February, 2010; accepted: 02 March, 2010; available on-line: 10 March, 2010

\section{INTRODUCTION}

Ethnopharmacological tradition followed by pharmacognosy and backed up by modern analytical techniques have provided numerous examples of plant-derived compounds which exhibit selective toxicity or otherwise distinct biological activity. Secondary plant metabolites not only provided the foundation of folk medicine and generations of traditional drugs, but also continue to be an inspiration for studies towards modern medicinal applications (Reuben et al., 2005; Dewick, 2009).

Isoflavones constitute a sub-class of flavonoids, a large family of secondary plant metabolites, which share common structural feature: a C6-C3-C6 sequence of the carbon skeleton, split into several variants of heterocyclic ring substitution pattern and diversified by a plethora of further modifications (Dixon, 1999; Wiseman, 2006; Veitch, 2007).

The role of isoflavones for the plant is not entirely clear and their target proteins are not known. It is likely that their formation has constitutive, as well as inducible determinants (Buer et al., 2007). Isoflavones are considered phytoalexins, which can also offer some marginal environmental advantage through allelopathic interactions. They possess antimicrobial and anti-insect activity, and induce nodulation genes in symbiotic Rhizobium bacteria. Nevertheless, it has to be stressed that the occurrence of isoflavones is quite limited in comparison with other types of flavonoids, like flavones, flavonols, anthocyanins, aurones, coumestans, etc. Plants known for significant isoflavone content are mainly found in the family of Fabaceae.

Water solubility of isoflavonoids is extremely low and their trafficking within a plant requires glycosylation, performed by ubiquitous glycosyltransferases (Offen et al., 2006; Noguchi et al., 2007).

Genistein (1), (Fig. 1) one of the most extensively studied isoflavones, as well as its analogs, are generally recognized as phytoestrogens. In fact, they can exert estrogenic as well as anti-estrogenic action, which is sometimes connected with animal reproduction problems (Leopold et al., 1976; Jefferson et al., 2007; Eustache et al., 2009).

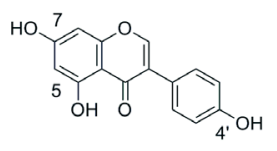

1

Figure 1. Genistein

The interest in genistein, as a potential chemopreventive agent or a drug supplementing treatment of relevant diseases arose with the discovery of estrogenic properties of isoflavonoids. This property suggests genistein use as a diet supplement relieving side effects of estrogen deficiency in menopausal women. On the other hand, the discovery of cytotoxic and antiproliferative activity of genistein, via inhibition of tyrosine kinases (Akiyama et al., 1987) and topoisomerase II (Markovits et al., 1989), as well as G2/M block of the cell cycle (Matsukawa et al., 1993) has suggested possible application of genistein in anticancer therapy.

Anticancer properties of genistein deduced from the results of in vitro experiments have been supported by epidemiological observations, indicating that increased soy consumption is related to lower risk of cancer development and cancer-related death especially in the case of breast and prostate cancer (Adlercreutz et al., 1993; Morton et al., 1997; Hussain et al., 2002; Magee \& Rowland,

Me-mail: arusin@io.gliwice.pl

Abbreviations: ALL, acute lymphoblastic leukemia; CF, cystic fibrosis; CFTR, cystic fibrosis transmembrane regulator; EGF, epidermal growth factor; EGFR, epidermal growth factor receptor; ER, estrogen receptor; GAGs, glycosaminoglycans; LDL, low density lipoprotein; MPs, mucopolysaccharidoses; MTT, 3-(4,5-dimethylthiazol-2yl)-2,5-diphenyltetrazolium bromide; Ox-LDL, oxidized low density lipoprotein; SERM, selective estrogen receptor modulator; UDPG, uridine diphosphoglucose. 
2004; Holzbeierlein et al., 2005; Chan et al., 2005; Sonn et al., 2005).

Although genistein exhibits biological activity of potential medicinal interest, there are also some drawbacks to be considered, limiting its prospective application in clinical practice. Among the most important are: relatively low concentration in the blood following per os application, due to relatively poor absorption from the intestine, rapid biotransformation in vivo into inactive metabolites, and ineffective accumulation in cells and tissues (Dixon \& Ferreira, 2000; Shellnut et al., 2002; Simons et al., 2010). At least some of these unfavourable features are believed to be diminished by chemical modification of genistein. But it is also expected that some genistein derivatives could exhibit increased selectivity to known molecular targets or acquire activity directed against novel ones.

The biological and biochemical activity of genistein, its potential chemopreventive and therapeutic properties, as well as genistein affinity towards a large variety of molecular targets have been reviewed in several excellent articles (Sarkar et al., 2006; Banerjee et al., 2008; Meeran \& Katiyai, 2008; Sakai \& Kogiso, 2008). The aim of this article is to present current findings concerning possible clinical applications of selected novel synthetic derivatives of genistein and some basic information on chemical reactivity of genistein, relevant to the synthesis of its derivatives.

Among many arguments cited in favour of synthetic analogs of genistein as prospective new drug candidates, in our opinion two are particularly convincing:

- the natural pool of the isoflavone consists of three different types of chemical entities — the aglycone, glucoside and acylated glucosides, which apparently facilitates trafficking and compartmentalization in plant tissue and may have a profound effect on the bioavailability and pharmacokinetics in humans;

- genistein, even though practically insoluble in water in its basic form and poorly bioavailable as aglycon, exhibits pleiotropic biological activity. This indicates the existence of multiple molecular targets, and an obvious potential of tuning up the drug's affinity by its derivatization.

\section{SEARCH FOR GENISTEIN DERIVATIVES EXHIBITING INCREASED INHIBITORY ACTION AGAINST TYROSINE KINASE}

One of the early observations relevant to possible anticancer applications of genistein concerned the inhibition of tyrosine kinases, including c-Src and v-Abl (Akiyama et al., 1987). These enzymes catalyze selective transfer of $\gamma$-phosphate groups from ATP to tyrosine residues of proteins, and this phosphorylation is important for controlling various signal transduction pathways involved in proliferation, differentiation, cell migration and many other cellular activities. Increased or aberrant expression or tyrosine kinases is regarded as one of important factors influencing tumour development and progression (Manash \& Mukhopadhyay, 2004; Shchemelinin et al., 2006).

The major structural features of genistein relevant to its inhibitory action against tyrosine kinase have been established by comparing the inhibitory effectiveness of several isoflavones with similar structure (daidzein, flavone, biochanin $A$, acacetin, prunetin, genistin). The rate of phosphorylation of A431 cell membranes induced by epidermal growth factor (EGF) in the presence of the above isoflavones indicated that critical for the inhibitory action of genistein is the $\mathrm{OH}$ group at $\mathrm{C}-5$, and that the presence of $\mathrm{OH}$ groups at the $\mathrm{C}-7$ and $\mathrm{C}-4$ ' positions is responsible for the highest inhibitory activity of genistein (Ogawara et al., 1989). Importantly, a bulky group at C-7 was found to abolish the inhibitory action of genistein.

Having in mind that substitution of the $\mathrm{OH}$ groups at C-4', C-5, and C-7 can interfere with the inhibitory activity of genistein, Ogawara et al. (1989) synthesized 23 derivatives of isoflavone with various groups attached to C-2. Each of those derivatives was tested for its cytotoxicity $\left(\mathrm{IC}_{50}\right)$ as well as the ability to inhibit tyrosine kinase activity. It was found that none of the tested drugs was more cytotoxic than genistein and none exhibited a greater anti-kinase activity.

Booth et al. (1999) synthesized a series of compounds with different pattern of methoxylation and oxygenation on the phenyl ring. However, none of those derivatives exhibited increased cytotoxic activity against colon cancer cells, and only one of them inhibited tyrosine kinase activity, albeit less efficiently than genistein. To our knowledge, the search for genistein derivatives able to inhibit tyrosine kinase activity more efficiently than genistein has turned out to be unsuccessful so far.

\section{GENISTEIN DERIVATIVES WITH THE ACTIVITY OF SELECTIVE ESTROGEN RECEPTOR MODULATORS (SERMS)}

It was recognized very early that the chemical structure of genistein bears strong similarity to $17 \beta$-estradiol, and that genistein binds to estrogen receptors (ER) and to sex hormone-binding globulins (Kuiper et al., 1998; Klinge, 2000; Kurzer, 2002). A functional interaction of genistein with estrogen receptors, leading to stimulation of ER responsive genes, was confirmed in multiple experiments in vitro (Birt et al., 2001; Kostelac et al., 2003; Zierau et al., 2006). Although genistein interacts with both $\mathrm{ER} \alpha$ and $\mathrm{ER} \beta$, it shows a much higher affinity (approx. 30 times higher) to ER $\beta$ (Pike et al., 1999). Moreover, the similarity of the mode of interaction between estrogen receptor and genistein to that of receptor and raloxifen (Pike et al., 1999) reasonably suggests that genistein should be classified as one of natural selective estrogen receptor modulators (SERMs) and not as an estrogen (Setchell, 2001). To some extent, genistein action resembles the effects of raloxifen on the skeletal system in ovariectomized mice (Śliwiński et al., 2009).

In order to increase the SERM properties of genistein a number of genistein derivatives have been synthesized and their binding to ER receptors assessed. One of them, 6-carboxymethyl genistein (6CG) (Fig. 2) (Somjen et al., 2002) was found to bind highly selectively to ER $\beta$, although the binding affinity was smaller than that of genistein. Interestingly, genistein and 6CG exhibited differential influence on DNA synthesis in human umbilical artery vascular smooth muscle cells. While low concentration of genistein $(30 \mathrm{nM})$ increased DNA synthesis induced by low concentrations of estrogen $(0.3 \mathrm{nM})$, an equivalent dose of 6CG had an inhibitory effect.

To find out whether the antiosteoporetic properties of genistein could be enhanced by its modification, Wang et al. (2005) synthesized, with the use of a sonochemical method, a number of genistein derivatives in which the C-7 or C-4' hydroxyl groups were substituted with various chemical groups (Fig. 3). 


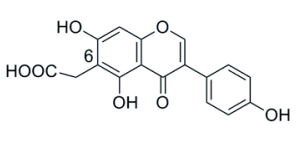

2

Figure 2. 6-Carboxymethylgenistein According to Somjen et al. (2002).

Those novel genistein derivatives, except the toxic ones, were subsequently administered to ovariectomized rats in which experimental osteoporosis had been induced by feeding the animals a low-calcium diet. The compounds, including genistein, were administered orally through a stomach tube at a dose of $25 \mu \mathrm{mol} / \mathrm{kg}$ per day. As a positive control, anti-17 $\beta$-estradiol was used at $0.5 \mu \mathrm{mol} / \mathrm{kg}$ per day. Two months later measurements of the femoral bone mineral density, and the level of alkaline phosphatase, a bone metabolic marker, were conducted.

Among seventeen novel genistein derivatives the authors found five compounds showing increased antiosteoporetic activity when compared to genistein. The best results were observed for 4',5,7-tri[3-(2-hydroxyetylthio) propoxy]isoflavone. All bioactive compounds showed no acute toxicity; they contained the 2-hydroxyetylthio motif, which the authors assumed to be a key pharmacophore, inhibiting bone loss during estrogen shortage.

\section{MODIFICATION OF GENISTEIN AIMED TO IMPROVE OR CHANGE ITS BIODISTRIBUTION}

\section{Conjugation of genistein with antibodies or peptide ligands}

One of the major strategies of targeted therapy is to construct two-domain drugs in which one domain recognizes the target cells, whereas the other one exerts a therapeutic activity. In order to selectively target genistein to transmembrane tyrosine kinases with their kinase domain localized intracellularly, Uckun et al. (1998) obtained via photochemical cross-linking a conjugate of genistein with epidermal growth factor (EGF), an epidermal growth factor receptor (EGFR) ligand. It was expected that internalization of this conjugate should increase the intracellular concentration of genistein leading to a more effective inhibition of the EGFR tyrosine kinase activity. Subsequent biodistribution studies in mice revealed that, as expected, the conjugated genistein was effectively taken up by cells, and the highest concentration of the conjugate was observed

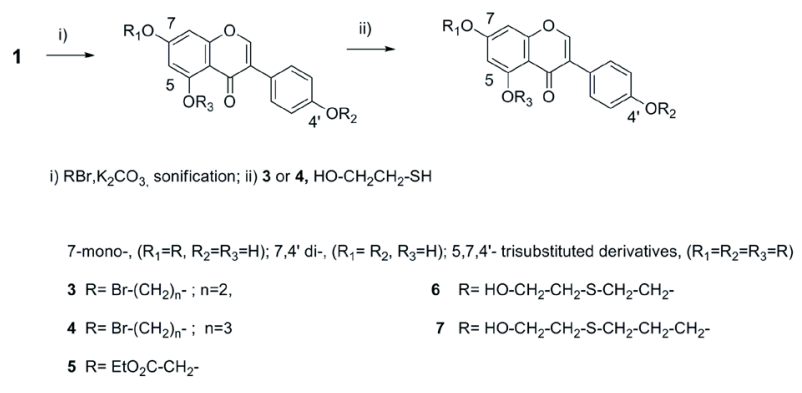

Figure 3. Derivatives of genistein with antiosteoporotic properties

According to Wang et al. (2005). in the liver and spleen. Unexpectedly, the authors observed low accumulation rate of the conjugate in human breast cancer cells (line MDA-MB-231) grown on SCID mice. However, mice treated intraperitoneally with the conjugate at $100 \mu \mathrm{g} /$ day for 10 days showed significantly better survival as compared to mice treated with adriamycin, cyclophosphamide or methotrexate. The best results were observed when the conjugate was administered for $24 \mathrm{~h}$ after subcutaneous inoculation of cancer cells, although the drug was shown to be effective also when administered to mice bearing tumours of a diameter less than $1 \mathrm{~cm}$.

A similar strategy was used for experimental treatment of leukemias. To that purpose tumour-bearing mice were treated with genistein conjugated to B43 antibody which recognized the C19 antigen, present on the surface of B lymphocytes and absent from plasma cells. CD19 is an adaptor protein for Lyn tyrosine kinase amplifying signals transduction from nonreceptor Src tyrosine kinases. The authors expected that, after internalization, the genistein conjugate with anti-CD19 antibody would block efficiently the Lyn kinase activity, leading to apoptosis of leukemic cells. The study was performed on SCID mice bearing human acute lymphoblastic leukemia (ALL) or non-Hodgkin's lymphoma (Ek et al., 1998). It was found that the conjugate was more effective therapeutically than cytostatics routinely used for treatment of this kind of leukemias. Subsequently, in order to determine whether the conjugate could be used for treatment of humans, a toxicity test was performed on cynomolgus monkeys (Messinger et al., 1998). The animals obtained various intravenous doses (1.7 to $6.8 \mu \mathrm{mol} / \mathrm{kg}$ per day) using various time schedules, and no toxic symptoms were observed during long term observation. At the same time it has been found that $t_{1 / 2}$ for the conjugate in the circulation was within the $10-23 \mathrm{~h}$ range. These highly encouraging results inclined the authors to perform phase I clinical study.

In the clinical trial (Uckun et al., 1999) genistein conjugate was applied to seven children and eight adults with acute lymphoblastic leukemia, for whom conventional therapies had failed. The conjugate was administered intravenously at daily doses of $0.1-0.32 \mathrm{mg} / \mathrm{kg}$ for 10 days or weekly at an appropriate dose. No severe side effects were observed and one remission and two temporary responses were noted, thus the authors assessed those results as encouraging.

\section{Complexes of genistein with piperazine}

The low solubility of genistein in aqueous solutions is regarded as a serious drawback limiting its therapeutic application. In order to increase the solubility, a complex of genistein with piperazine was obtained in which the $\mathrm{OH}$ group at $\mathrm{C}-7$ of genistein was bound to piperazine nitrogen by a hydrogen bond (Fig. 4) (Mazurek et al., 1998). The authors suspected that such a complex could function as a kind of prodrug slowly releasing genistein to aqueous media. Although the conjugate showed over 500 times better solubility than free genistein, the rate of genistein release was unsatisfactorily slow. Moreover, the in vitro cytotoxicity against HL-60 human mieloblastoma cells was similar for genistein and its conjugate with piperazine (Polkowski et al., 2000). In any case, the persistence of the complex in diluted aqueous solutions can be challenged on thermodynamic grounds. 


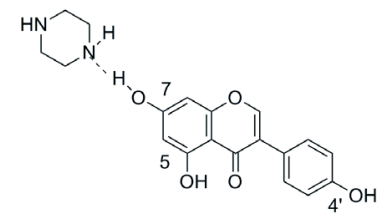

8

Figure 4. Adduct of genistein and piperazine According to Mazurek at al. (1998).

\section{Lipophilisation of genistein}

In order to improve the biological activity of genistein by increasing its rate of cellular uptake and to extend its stability as well as blood circulation Meng et al. (1999b) synthesized a number of fatty acid esters of genistein. Those were genistein 4'-stearate, genistein 7-stearate, genistein 4',7-distearate, genistein-4',-oleate, genistein-7oleate and genistein 4',7-dioleate (Fig. 5). The authors expected that these highly lipophilic genistein derivatives would be effectively incorporated into low density lipoproteins (LDLs), and that, similarly to cholesterol, they would be effectively transported into various tissues and taken up by cells via receptor-mediated endocytosis.

When tested for use in artificial LDLs, all the genistein oleates were much more effectively incorporated into these liposomes as compared to free genistein or the genistein stearates. Subsequent studies of the antiproliferative effect of the LDLs loaded with genistein derivatives against U937 cells (human leukemia) revealed that genistein-7-oleate and genistein-4',7-dioleate effectively inhibited incorporation of radioactive thymidine into DNA, while genistein-4'-oleate was ineffective (Meng et al., 1999a). The mechanism of the antiproliferative activity of the selected fatty acid esters of genistein has not been determined, however.

\section{GENISTEIN DERIVATIVES AS NO DONORS}

Nitrogen oxide (NO) is a well-known regulatory molecule involved in various cellular processes. Specifically, NO is involved in the regulation of contractility of vasculature thus maintaining vascular homeostasis (Miller \& Megson, 2007). Having in mind that various vascular diseases can be caused by aberrant functioning of tyrosine kinases, Matsumoto et al. (2005) decided to synthesize genistein derivatives which should potentially be able to inhibit tyrosine kinase activity and increase NO level. They synthesized two novel genistein derivatives 7-[(4-nitroxy)butyroyl]-genistein (12) and 7-[(4nitrooxymethyl)-( $\alpha$-methyl)phenylpropanyl]-genistein (13) (Fig. 6), and assessed their ability to relax rat endothelium-denuded aortic strips. Both derivatives and genistein itself induced aortic relaxation in the following

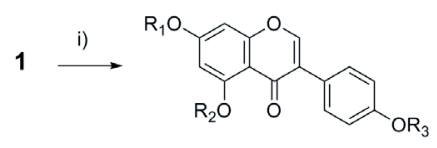

i) $\mathrm{C}_{17} \mathrm{H}_{33} \mathrm{COCl}$

$9 \mathrm{R}_{1}=\mathrm{C}_{17} \mathrm{H}_{33} \mathrm{CO}-; \mathrm{R}_{2}=\mathrm{R}_{3}=\mathrm{H}$

$10 \mathrm{R}_{1}=\mathrm{R}_{3}=\mathrm{C}_{17} \mathrm{H}_{33} \mathrm{CO}-; \mathrm{R}_{2}=\mathrm{H}$
$11 \mathrm{R}_{1}=\mathrm{R}_{2}=\mathrm{H} ; \mathrm{R}_{3}=\mathrm{C}_{17} \mathrm{H}_{33} \mathrm{CO}-$

Figure 5. Lipophilic esters of Genistein. According to Meng et al. (1999b)

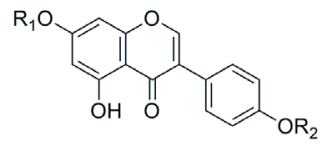

$$
12 \mathrm{R}_{1}=\mathrm{O}_{2} \mathrm{~N}^{-}
$$

Figure 6. Genistein derivatives as NO donors According to Matsumoto et al. (2005).

order: $\quad 7-[(4$ nitrooxymethyl $)-(\alpha-$ methyl $)$ phenylpropanoyl $]$ genistein > 7-[(4-nitroxy)butyroyl]-genistein > genistein. The relaxation induced by 12 and 13 was abolished by a guanylyl cyclase inhibitor, proving that the genistein derivatives indeed acted as $\mathrm{NO}$ donors.

When rat aortic strips in the experimental system described above were treated with lysophosphatidylcholine (LPC), a major phospholipid component of oxidized low-density lipoprotein (Ox-LDL), critically implicated in the atherogenic activity of Ox-LDL through an involvement of tyrosine kinase, the relaxation induced by 12 and 13 was abolished. The above observations confirmed the authors' expectations that the genistein derivatives 12 and 13 exhibit NO donor capacity and exert their inhibitory effect against tyrosine kinases.

Nitric oxide also plays an important role in bone metabolism. The drugs being NO donors effectively counteract bone mass loss occurring due to reduced rate of estrogen biosynthesis in postmenopausal women (Wimalawansa, 2000). What is particularly important, the NO donors not only slow down the rate of bone resorption, but also stimulate proliferation of osteoclasts (Hukkanen et al., 2003).

In order to find a bifunctional derivative of genistein having both estrogenic properties suitable for hormone replacement therapy and being an effective nitric oxide donor able to restrain bone loss in postmenopausal women, Wang et al. (2007) synthesized genistein 7,4'-(nitroxy) butyrate (14). Its NO-releasing capacity was studied in vitro using MC3T3-E1 cells, an immature osteoblastic cell line derived from calvaria of newborn C57BL/6 mouse. It has been demonstrated that NO is released from derivative $\mathbf{1 4}$ less rapidly and for a longer time than from glyceryl trinitrate (GTN), the classical NO donor routinely used in medical treatment (Wang et al., 2007). Using MT'T assay and flow cytometry it was determined that 14 stimulated growth of MC3T3-E1 cells in a doseand time-dependent manner, with the highest stimulatory effect observed for treatment of cells with $1 \mathrm{nM}$ NOgenistein for $48 \mathrm{~h}$, albeit the stimulation was weaker than that observed for an optimal concentration of estradiol. In order to determine whether NO-genistein is able to stimulate differentiation of osteoblasts the authors measured the activity of a bone-specific isoform of alkaline phosphatase and the expression of osteocalcin, a specific marker for late osteoblast differentiation, as well as the rate of formation of calcific deposition. All those assays showed that derivative 14 stimulated osteoclast differen- 


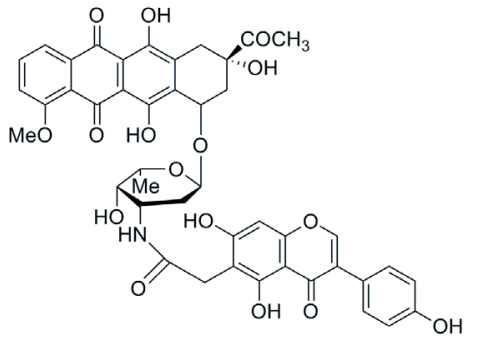

15

Figure 7. Conjugate of daunomycin with genistein According to Somjen (2003).

tiation and mineralization more effectively than genistein, glyceryl trinitrate or combination of the two. Although the effect of 14 was less pronounced than that of estradiol, Wang et al. (2007) concluded that 14 could be an interesting drug for treatment of postmenopausal osteoporosis.

\section{GENISTEIN AS A VEHICLE OF SELECTED CYTOSTATIC DRUGS}

It has been suggested that the affinity of genistein or its derivatives for estrogen receptors (ERs) could be used to target cytotoxic drugs to cancer cells that express membrane form of ER (Somjen et al., 2003). The authors synthesized a conjugate of daunomycin and 6-carboxymethyl genistein (2), the derivative described above (Fig. 7). This conjugate (15) was used for treating NCIH295R human adrenocortical cancer cells which express estrogen receptor on their surface. It was found that at low concentrations $(0.3-30 \mathrm{nM})$ the conjugate inhibited cell proliferation more effectively than free daunomycin. However, at higher doses (300-3000 nM) the toxicities of free and genistein-conjugated daunomycin (15) were similar.

\section{SYNTHETIC GENISTEIN DERIVATIVES OF ANTICANCER ACTIVITY}

A significant step in the search for genistein derivatives with anticancer activity was the synthesis of nine genistein glycosides of which some turned out to inhibit proliferation of various cell lines in vitro (Polkowski et al., 2004). The structure of the most active compound, (16) termed G21, is shown in Fig. 8.

This genistein derivative has the following structural characteristics: acetylated sugar hydroxyls, a double $\mathrm{C}=\mathrm{C}$ bond in the sugar molecule binding directly to aglycone, $\alpha$ configuration of the genistein-sugar glycosidic bond, and localization of the sugar substituent at the $\mathrm{C} 7-\mathrm{OH}$

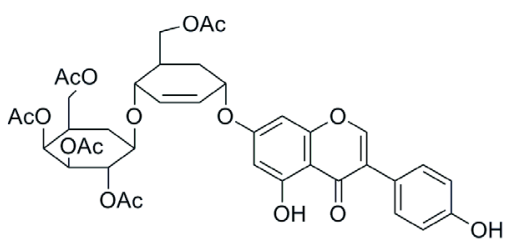

16

Figure 8. Glycoside of genistein inhibiting microtubule polymerization

According to Rusin et al. (2009). position in the genistein molecule. Further studies of the properties of G21 demonstrated that its $\mathrm{IC}_{50}$ was around $5 \mu \mathrm{M}$, thus approx. 10 times less than that of genistein. The structure of the molecule was stable, and its toxicity against cancer cells was higher than against normal ones (Popiołkiewicz et al., 2005). A preliminary characterization of G21 concluded that this novel genistein glycoside did not hydrolyze under in vitro cell culture conditions and that the structural feature critical for its high cytotoxicity was the double $\mathrm{C}=\mathrm{C}$ bond in the sugar moiety directly bound to $\mathrm{C} 7$ of the aglycone as well as acetylation of $\mathrm{OH}$ groups in the sugar residue (Ksycińska et al., 2004).

A search for the mechanism of G21 cytotoxicity has revealed an unexpected feature of this compound. It was found that G21 is able to disrupt the microtubule network and to affect the structure of centrosomes, causing the appearance of aberrant mitotic spindles. In an in vitro assay the polymerization of purified bovine brain tubulin was inhibited by G21, indicating that this compound interacted with tubulin directly (Rusin et al., unpublished). Moreover, treatment of cells with G21 led to the generation of micronuclei containing centromeric markers, which was not observed when cells were treated with genistein. Thus G21, unlike genistein, exhibits aneugenic properties. These observations reveal that, G21 is the first derivative of genistein able to substantially affect microtubule dynamics.

In our preliminary studies we also found that several genistein derivatives with a sugar moiety linked to genistein by a $2-5$ carbon atom spacer possessed stronger antiproliferative activity. One of them blocked the cell cycle in the G2/M phase and destroyed the structure of mitotic spindle, thus resembled mode of action of G21 (Rusin et al., unpublished).

The derivatives for which antiosteoporotic action had previously been reported (Wang et al., 2005) were also screened for anti-proliferative potential (Li et al., 2006). In their screening studies $\mathrm{Li}$ and coworkers tested 30 new derivatives (Fig. 3) (among them several ones not previously described) for their ability to inhibit proliferation of KB cells. They found several derivatives with increased antiproliferative potential.

In another study aimed at obtaining novel genistein derivatives with potential anticancer activity Zhang et al. (2007) synthesized a series of 24 derivatives containing the alkyl spacer between C7 of genistein and amines. One of the main goals was to determine how the length of the spacer linking amine residue to the genistein influences cytotoxicity of these novel genistein derivatives. The cytotoxicity study was performed using $\mathrm{KB}$ and K562 cells and it was found that only few genistein derivatives were more active than the parent drug, having $\mathrm{IC}_{50}$ of about 7-10 $\mu \mathrm{M}$ (Zhang et al., 2007). The most active were the derivatives with the amine group sepa-<smiles>[R]Oc1ccc(-c2c(CCCC(=O)NCCNC(=O)OC(C)(C)C)oc3cc([3H])cc(O)c3c2=O)cc1</smiles>

$$
\begin{aligned}
& 17 \mathrm{R}=\mathrm{H} \\
& 18 \mathrm{R}=\mathrm{Me}
\end{aligned}
$$

Figure 9. Amide of 2-carboxypropylgenistein exhibiting high antiproliferate activity

According to Kohen et al. (2007). 
rated from genistein by a three-carbon chain. However, the mechanism of the increased cytotoxic activity has not been determined.

A novel genistein derivative exhibiting significantly higher antiproliferative activity than the parent drug was recently obtained by Kohen et al. (2007) by attaching an $\mathrm{N}$-tert-butoxycarbonylo-1,6-diamino-hexane group to C2 of genistein (Fig. 9). Although this novel genistein derivative did not show estrogenic activity, it may interact somehow with estrogen receptor. The antiproliferative activity was shown to be different in estrogen-sensitive cancer cell lines expressing $E R \alpha$ and ER $\beta$ mRNA at different ratios. The highest antiproliferative effect measured by radioactive thymidine incorporation was observed for an estrogen-sensitive colon cancer cell line (320DM), and the lowest for an ovarian cancer cell line (A2780). Interestingly, the genistein derivative was more toxic for cells that preferentially expressed mRNA for $E R \beta$ relative to $E R \alpha$. Moreover, the drug in general inhibited more effectively the proliferation of cancer cells than that of normal vascular smooth muscle cells.

Apart from the genistein derivative described above, Kohen et al. (2007) also synthesized similar derivatives of biochanin (2-[3-carboxy-(6-tert-butoxycarbonylamino)hexylamino-propyl]-7,5-dihydroxy-4'-methoxyisoflavone) and daidzein (5-[2-[3-(4-hydroxy-phenyl)-4-oxo-4H-chromen-7-yloxy]-acetylamino]-pentyl)-carbamic acid tertbutyl ester). These compounds also did not exhibit estrogenic properties. Of all the derivatives of isoflavones tested by Kohen et al. (2007), the highest antiproliferative activity was shown for the $\mathrm{N}-\mathrm{t}-\mathrm{Boc}$ derivative of $7-(O)$ carboxymethyl daidzein.

A series of chemically modified daidzein derivatives $\left(2,7,4^{\prime}\right.$ substituted) were also prepared by Davis et al. (2008). Those compounds were found to bind with low affinity to $E R \beta$ receptor and to inhibit proliferation of hormone-dependent and hormone-independent breast cancer cell lines, thus confirming that isoflavone derivatives act on multiple signaling pathways, not necessarily mediated by ER, leading to the activation of cell death mechanisms.

\section{GENISTEIN DERIVATIVES WITH ANTIMICROBIAL AND ANTIPARASITIC ACTIVITY}

Various flavonoids and isoflavonoids are recognized as antibacterial, anti-viral and anti-fungal agents (Cowan, 1999). Genistein has with antimicrobial properties (Dixon \& Ferreira 2002; Verdrengh et al., 2004; Hong et al., 2006; Ulanowska et al., 2006). Cell survival studies suggest that genistein is a bacteriostatic rather than a bactericidal agent (Ulanowska et al., 2007). Some reports indicate that the potent antibacterial properties of genistein shown in vitro may be mediated by the stabilization of the covalent topoisomerase II-DNA cleavage complex (Verdrengh et al., 2004). Nevertheless, the exact mechanism of antimicrobial action of genistein remains largely unknown. The concentration of genistein necessary for antimicrobial action is relatively high $(100 \mu \mathrm{M})$.

The derivatisation of genistein leading to an increased antibacterial and antifungal activity was reported by Zhang et al. (2008). They prepared three series of derivatives in which the genistein ring system was linked to the heterocyclic moieties with 2-carbon, 3-carbon or 4-carbon spacers (Fig. 10). Among the compounds tested some $(19,20,21,22$ and 23$)$ exhibited good antibac-
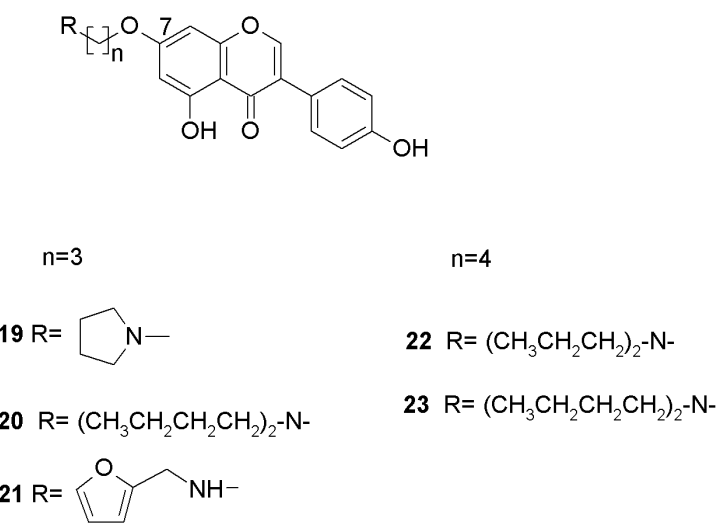

Figure 10. 7-0-modified derivatives of genistein exhibiting antibacterial activity

According to Zhang et al. (2008).

terial activities, while 19 also showed notable antifungal activity. The activity of the mentioned derivatives was several fold better than that of genistein.

An antimicrobial activity of genistein derivatives was also described by Li et al. (2008). They synthesized and tested 14 new deoxybenzoin derivatives of genistein (Fig. 11) and found that dimeric deoxybenzoin (24-28) derivatives are generally more active than genistein and deoxybenzoins against selected microorganisms.

Genistein derivatives are also described as potential agents to treat parasitic diseases. Interesting examples suggesting that isoflavones have the potential for antiprotozoan therapies were reported by Gargala et al. (2005) and Stachulsky et al. (2006) and for anti-helminthic therapies by Naguleswaran et al. (2006). Gargala and coworkers examined activities of fifty-two dihydroxyisoflavone and trihydroxydeoxybenzoin derivatives on Neospora caninum, Sarcocystis neurona and Cryptosporidium parvum development in vitro. They also assessed the effects of two agents selected in in vitro screening: 3'-bromo and 4'-bromo genistein in Cryptosporidium parvum-infected immunosuppressed gerbils. They found more effective the abolishment of fecal microscopic oocyst shedding after administration of these two compounds than after nitazoxanide or paromomycin, two routinely used drugs.

Some of the derivatives described by Gargala et al. (2005) were also tested for inhibitory effects on the development of tapeworms Echinococcus sp. (Naguleswaran et al., 2006). They found that two of the genistein deriva-<smiles>[R]Oc1ccc(CC(=O)c2c(O)c(O)cc([R6])c2Cc2c([R20])cc([R20])c(C(=O)Cc3ccc([R2])cc3)c2O)cc1</smiles>
$24 \mathrm{R}=\mathrm{H}$;
$25 \mathrm{R}=\mathrm{Me}$
$26 \mathrm{R}=\mathrm{HOOCCH}_{2}-$
$27 \mathrm{R}=\mathrm{Br}\left(\mathrm{CH}_{2}\right)_{3}-$
$28 \mathrm{R}=\mathrm{Br}\left(\mathrm{CH}_{2}\right)_{4}$

Figure 11. Deoxybenzoin derivatives of genistein

According to Li et al. (2008). 
tives (2'-bromo-and 6'-bromo genistein), induced considerable damage in E. granulosus protoscoleces, rendering them nonviable. Although genistein is a potent inhibitor of Echinococus larvae development, prolonged treatment with this isoflavone may cause adverse effects from the undesired stimulation of ER. The above mentioned genistein derivatives do not bind to ER and there is no risk of side effects caused by a phytoestrogen.

It is also worth mentioning that some of the isoflavone derivatives may act selectively, having excellent antiparasitic activity and lacking antibacterial activity (Stachulsky et al., 2006). The absence of antibacterial properties is advantageous, because it allows avoiding the development of further resistant bacterial strains.

The examples mentioned above demonstrate that synthetic isoflavones exhibit distinct effects on parasites and could be potentially exploited further in the development of novel chemotherapeutic tools against infections by protozoa and larval-stage helminthes.

\section{GENISTEIN AND ITS DERIVATIVES FOR TREATMENT OF MUCOPOLYSACCHARIDOSES AND CYSTIC FIBROSIS}

Mucopolysaccharidoses (MPs) are inherited metabolic disorders caused by mutations leading to dysfunction of one of the enzymes involved in the degradation of glycosaminoglycans (GAGs). An impairment of GAGs degradation leads to their accumulation in patients' cells and this causes dysfunction of tissues and organs. Genistein has been recently reported to inhibit the synthesis of GAGs in cultured fibroblasts from MPS patients (Piotrowska et al., 2006). Prolonged cultivation of those cells in the presence of genistein resulted in the reduction of GAG accumulation and normalization of cells, as estimated from biochemical tests and electron microscopic analysis. Genistein also reduces lysosomal storage in peripheral tissues of mucopolysaccharide IIIB mice (Malinowska et al., 2009). A recent pilot clinical study indicated that such a therapy may be effective in MPS III (Sanfilippo syndrome) (Piotrowska et al., 2008). It must be noted, however, that genistein content differs in commercially available soy products. Some of them may be useless for MPS treatment and the use of pure synthetic genistein may be an option (Piotrowska et al., 2009). The mechanism of genistein-mediated inhibition of GAG synthesis relies on epidermal growth factor (EGF)dependent pathway (Jakóbkiewicz-Banecka et al., 2009). Based on several human fibroblast culture experiments, it was found that some synthetic genistein derivatives inhibit GAG production by up to $90 \%$ in fibroblasts from MPS patients of various types (Kloska et al., 2006).

Of 20 synthetic genistein derivatives tested with MPS III human fibroblast cultures, five showed an inhibitory effect on GAG synthesis similar to genistein or even higher.

Genistein was shown to partially activate the defective chloride channels (cystic fibrosis transmembrane regulator, CFTR) associated with cystic fibrosis (CF). Not only does it partially restore the CFTR activity but in addition it augments CFTR maturation and increases its localization at the cell surface (reviewed by Wegrzyn et al., 2009). This dual mode of action along with its low toxicity places genistein among candidates for CF therapeutics. Pre-clinical studies with genistein have provided a basis for clinical trials with CF patients. Currently, a Phase II clinical trial is underway; it investigates the effects of combined treatment (4-phenylbutyrate and gen- istein) in CF patients with the $\Delta \mathrm{F} 508$ mutation. (Clunes \& Boucher, 2008). Although genistein derivatives for potential treatment of cystic fibrosis have not been studied extensively yet, the work of Gallieta et al. (2001) justifies the search for new compounds based on the structure of this isoflavonoid. Gallieta and coworkers generated a combinatorial compound library based on two lead compounds, flavones and benzo[c]quinoliziniums, which are believed to activate CFTR $\mathrm{Cl} 2$ conductance by direct interaction with the CFTR molecule. Several novel CFTR activators were identified. Interestingly, the structures of a high potency to activate CFTR, the 7,8-benzoflavones contained features of both flavones and benzo[c]-quinoliziniums.

\section{REACTIVITY OF GENISTEIN AND SYNTHESIS OF ITS ANALOGS}

It is obvious from the structural formula of 1 that its multifunctional features offer ample opportunity for derivatization, but screening of the chemical literature allows one to conclude that this potential has not been explored extensively thus far. Most of the published studies have concentrated on functionalization of hydroxyl groups. By virtue of its three phenolic groups, at C-5, C-7 and C-4', genistein is a very weak Bronsted acid. In principle these groups can all be functionalized in typical $\mathrm{O}$-acylation or O-alkylation reactions. The question of selectivity of such substitutions is related to the susceptibility for deprotonation, which has been studied spectroscopically; in conclusion, the acidity of phenolic groups in 1 , under a variety of aqueous environment conditions, is as follows: $7-\mathrm{OH}>4$ ' $-\mathrm{OH}>5-\mathrm{OH}$ (Zielonka et al., 2003). The corresponding rate constants differ by approximately two orders of magnitude between successive pairs of $\mathrm{OH}$ groups. Additionally, 5-OH is practically eliminated from competition because of its engagement in a strong intra-molecular hydrogen bond with the C-4 carbonyl group. Therefore, it has been postulated that selective substitution at $7-\mathrm{OH}$ or 4'-OH can be achieved either directly, or stepwise, by adopting a protecting group strategy. Indeed, Lewis et al. (2000) in their studies have demonstrated that genistein monoanions, generated by the action of strong bases in organic solvents, can be selectively alkylated and acylated at C-7 (29), while the corresponding dianions obtained under similar conditions can be selectively substituted at C-4' when treated with one equivalent of a derivatizing reagent (30), pointing to the higher nucleophilicity of the less acidic phenolic group (Fig. 12). This approach has allowed ob-

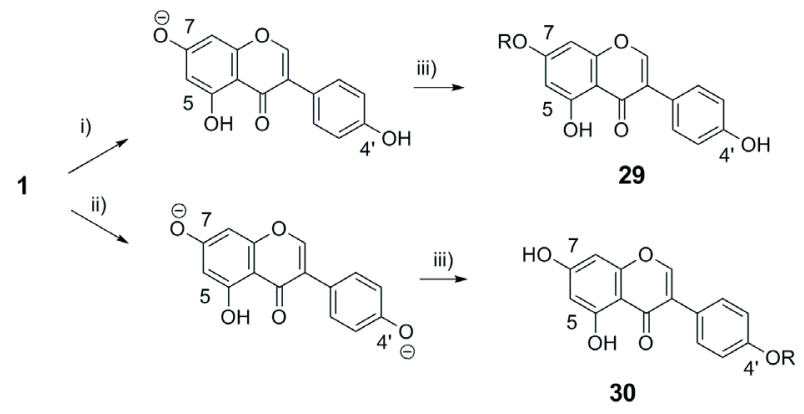

i) strong base,1eq; ii) strong base, 3eq iii) $\mathrm{RCl}, 1$ eq ; R= palmitoyl, oleoyl,stearoyl

Figure 12. Selective acylation of genistein According to Lewis et al. (2000). 


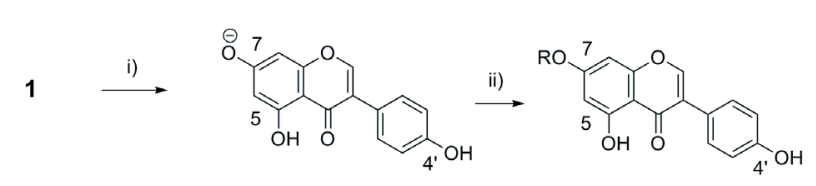

i) $\mathrm{Bu}_{4} \mathrm{NOH}$ ii) $\mathrm{RCl}$; $\mathrm{R}=\mathrm{Me}_{3} \mathrm{Si}-; \mathrm{C}_{6} \mathrm{H}_{5} \mathrm{CH}_{2}$

i) $\mathrm{K}_{2} \mathrm{CO}_{3}$ ii) alkyl bromide, microwave irradiation

Figure 13. Regioselective alkylation of genistein According to Wang et al. (2005).

taining a variety of lipophilic esters of 1 , by reacting its anions with palmitic, stearic and oleic acid chlorides.

However, the reactivity of $\mathbf{1}$ is not limited to simple ionic reactions depicted above. Phenolate anions are susceptible to secondary transformations initiated by Sequential Proton Loss Electron Transfer leading to the formation of hydroxyl radicals, which are particularly important for in vivo interactions of polyphenolic molecules (Musialik et al., 2009).

Attempts of direct functionalization of 1 have often been hampered by the difficulties in its solubilization under typical acylation/alkylation reaction conditions. In order to overcome this problem, sonication has been used extensively to activate reactants surface in heterogeneous reaction mixtures (Guilet et al., 1998; Li et al., 2002; Hofmann, 2003; Bonrath, 2004; Wang et al., 2006; Li et al., 2006; Zhang et al., 2008). In an analogous manner, microwave irradiation has been applied as a mean for enhancing molecular energy transfer to facilitate acylation and alkylation reactions involving 1 (Fig. 13) (Wang et al., 2005).

Although 1 is easily degraded under strong alkaline conditions, we found that it can form stable salts with strong bases. These salts can be useful intermediates for further derivatization of 1 . In particular, it has been demonstrated that one such intermediate, mono tetra-N(n-butyl) ammonium salt of genistein greatly facilitates its selective silylation, acylation and alkylation (Grynkiewicz et al., 2004).

This finding allowed facile synthesis of a series of 7-O-benzylated derivatives of 1 that were later studied as molecular probes modifying experimental and biological lipid membranes (Środa et al., 2008).

Genistein easily undergoes single and double 7,4'-Osilylation in dimethylformamide and in the presence of imidazole as a base. Derivatives bearing tert-butyldimethylsilyl residues are isolable as stable intermediates, featuring some unexpected reactivity (Szeja et al., 2003). In particular, in the presence of a typical acylation $\left(\mathrm{Ac}_{2} \mathrm{O} /\right.$ $\mathrm{Py}$ ) mixture the sililoxy group can be selectively replaced by an acetoxy residue. When phthalic anhydride is used as the acyl component, selective deprotection takes place.

Since genistein, like other flavonoids, occurs in nature principally as a glycosides, chemical glycosylation as a way of forming libraries of new chemically diversed compounds is an obvious strategy. Unfortunately, most methods known are not well suited for complex multifunctional aglycones (Grynkiewicz et al., 2008). The strategy of using lipophilic protecting groups, which facilitate solubility of substrates in organic solvents and reduce multiple reactive centers, proved, again, reasonably successful, even with traditional procedures like the Koenigs-Knorr method (Nishiyama et al., 1993; AlMaharik \& Botting, 2006). Glycosylation of unprotected
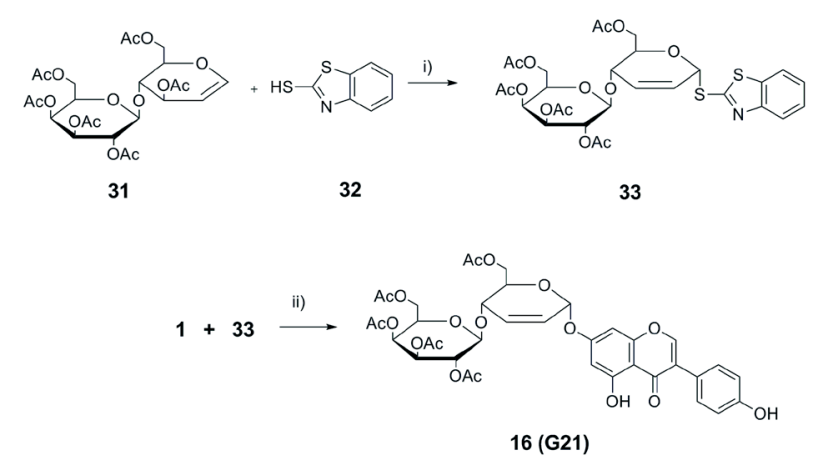

i) $\operatorname{lnCl}_{3}$, methylene chloride; ii) $\mathrm{Cu}(\mathrm{OTf})_{2}$, methylene chloride

Figure 14. Stereoselective synthesis of genistein glycoside According to Rusin et al. (2009).

genistein with acetobromoglucose, aimed at obtaining a derivative with 7-O- $\beta$-D-configuration was first described in 1943 by Zemplen and Farkas (1943) who reported $17 \%$ yield.

In recent years, owing to special deprotonation design, various procedures involving phase-transfer catalysis succeeded in attaining 7-O- as well as 4'-O- regioselectivity, also with relatively low yields (Lewis et al., 1998; Lewis \& Wähälä, 1998). Another method of glycosylation of 1 involves exchange of an anomeric ester group. Thus when 1 was reacted with tetra- $O$-acetyl- $\alpha, \beta$-D-ribofuranose in the presence of tin tetrachloride, this yielded an anomeric mixture of 4'-O-ribofuranosides (about 26\%) in which the $\beta$-anomer prevailed (Boryski \& Grynkiewicz, 2001).

With respect to the mechanism of intermediate carboxonium ion generation, the application of glycals to the synthesis of glycosides is similar to the ribofuranose case presented above. The obtained products, however, are unsaturated and rearranged with respect to the position of the leaving group (Ferrier rearrangement) (Ferier \& Zubkov, 2003). Rather unexpectedly, this useful transformation failed to work in our hands when applied to 1 , although different glycals and a number of various Lewis acid catalysts were tried. Thus, unsaturated pyranosides of 1 were obtained by a stepwise procedure in which the rearrangement performed with water as the nucleophile was followed by esterification and anomeric exchange of the unsaturated ester, catalyzed by a palladium complex (Polkowski et al., 2004).

This reaction, when compared with model Ferrier rearrangement, suffers unfortunately from low regio- and stereoselectivity. Since one of the genistein unsaturated glycosides, G21, interfered with tubulin organization and cell cycle progression, resulting in pronounced cytostatic effect, a more selective method of its preparation was sought (Rusin et al., 2009). Consequently, for efficient preparation of G21, a 2-mercaptobenzotiazole intermediate was proposed as the leaving group, instead of a carbonate ester (Fig. 14).

Information on skeletal modifications of 1 , involving $\mathrm{C}-\mathrm{C}$ bond formation is scant and not encouraging. A notable exception results from applying higher carboxylic acid esters to the isoflavone synthesis pathway, which involves cyclization of a deoxybenzoin type intermediate, giving rise to 2 -substituted genistein derivatives which bear $\alpha$-ketoalkyl substituents. Introduction of a phenolic (or thiophenolic) substituent at C-2 of the benzochromanone ring was achieved by exchanging methylsulfone substituent (Kim et al., 2003). Substitution at position 2 
of the isoflavone skeleton is relatively easy to achieve, via a novel cyclization reaction in which 2-acyloxy deoxybenzoins can be transformed into 2-alkyl isoflavones (Pelter et al., 1998; 1999).

Successful triple hydroxymethylation of daidzein (structural analog of 1 without the C-5 hydroxyl group) with aqueous basic solution of formaldehyde indicates that similar condensations might be also possible for $\mathbf{1}$ (He et al., 2008). 6-Carboxymethyl genistein has been recognized as a novel synthetic estrogen receptor modulator and suitable substrate for preparing conjugates with anthracyclines (Somjen et al., 2002). This compound was obtained in low yield by treatment of 1 with bromoacetic acid and sodium in propanol under heating (Kohen et al., 1999; 2007).

Other structural modifications of genistein, like halogenation, nitration, sulfonation etc., are possible owing to the reactivity typical for aromatic compounds (Soidinsalo \& Wähälä, 2004; Wang et al., 2005).

The closest analogs of 1 are the compounds obtained by exchanging one or several atoms with their stable or radioactive isotope (typically deuterium or carbon 13 or 14). Such compounds are invaluable in studies of biodistribution, pharmacokinetics and metabolism because they are good markers in HPLC analysis with mass spectrometry detection (Prasain et al., 2004; Grynkiewicz et al., 2005). A number of special synthetic procedures have been designed for the synthesis of labeled genistein; they have been sucessfuly applied in an increasing number of biochemical and pharmacological studies (Wähälä \& Rasku, 1997; Whalley et al., 2000; Coldham \& Sauer, 2000; Oldfield et al., 2007).

\section{CONCLUDING REMARKS}

There is no doubt that genistein is, like so many other secondary metabolites, a semiotic molecule (Barbieri, 2008; Iriti \& Faoro, 2009). The belief that compound 1 can be successfully modified to become a more selective and more efficacious biologically active agent has rational foundations but so far chemical synthetic efforts have been poorly synchronized with biochemical findings. Genistein has become an obvious candidate for drug development because of its known molecular targets, but also out of the pressing needs for improvement of bioavailability and slowing down its in vivo conjugation and excretion. Interestingly, despite the known shortcomings of this secondary metabolite, there are numerous genistein-containing dietary supplements; this is accompanied by a remarkable persistence in the efforts to elevate the substance to the level of a registered active pharmaceutical ingredient (Grynkiewicz, 2002). Presently over 20 clinical trials of compound $\mathbf{1}$ are carried out in the USA alone, mainly for hormone-dependent ailments, including menopause symptoms, osteoporosis, and cancer (including its chemoprevention). At least three pharmaceutical products containing a defined dose of compound 1 made it to the market with clear medical indications: GCPTM (genistein-containing polysaccharide, Amino Up Chemical Co., Japan) as an anticancer drug; and Bonistein $^{\text {TM }}$ (DSM Nutritional Products, Netherlands) and Fosteum $^{\mathrm{TM}}$ (Primus Pharmaceuticals, USA), both for improving osteoporotic bone structure (Yuan et al., 2003; Ullmann et al., 2005; Squadrito et al., 2009).

This review testifies to the considerable synthetic effort made towards "better genistein" or "more efficient pro-genistein". Biological activity of the novel synthe- sized genistein derivatives seems to indicate ample space for designing new drugs; increasing structural complexity of the parent compound can bring about incremental increases of efficacy, radical changes in selectivity or even the appearance of a new mechanism of action. Although some new leads have emerged, the way to a validated drug candidate still seems quite distant.

It should not be overlooked that, besides adding new functionalities to the parent structure by chemical derivatization, an opposite tendency has also been followed, i.e. reducing some functional groups from compound 1. This was apparently inspired by findings concerning isoflavone metabolism in experimental animals and humans (Setchell et al., 2002). (S)-Equol, identified as the main mammalian metabolite of daidzeine (minor isoflavone constituent of legumes), has indeed been shown to exert a much more powerful estrogenic action than plant isoflavones. Equol can be relatively easily obtained synthetically, as well as by biotransformation, which makes it an interesting candidate for drug development (Heemstra et al., 2006). The reductionist approach to compound 1 structure-activity relationship resulted in two more synthetic compounds emerging in new drug registration area. First, phenoxodiol (dehydroequol) is a new FDA fast-track-to-registration drug investigated as a chemosensitizer for platinum and taxanes (Silasi et al., 2009). The second drug, ipriflavone, which was designed not to affect estrogenic receptors and is thus devoid of free hydroxyl groups, first became a hit as an over-thecounter non-steroidal anabolic, but was also registered as inhibitor of bone resorption and anti-osteoporosis drug (Agnusdei \& Bufalino, 1997).

It is especially interesting that in the recent studies particular attention is paid to genistein derivatives as effective radio- and chemosensitizers. As stated above a substantially greater effort is required in investigating more thoroughly the cytotoxicity mechanisms of novel genistein derivatives. The chemistry of compound 1 remains opportunistic and limited to easy-to-perform procedures. Undoubtedly, more information about specific biological targets of genistein derivatives obtained so far is needed before a good drug candidate can emerge from the new compound libraries presented in this review.

\section{Acknowledgements}

This work was supported by the grants of the Ministry of Science and Higher Education: PBZ-MNiI-1/1/2005 and POIG 01.01.02-14-102/09.

\section{REFERENCES}

Adlercreutz HA, Makkanen H, Watanabe S (1993) Plasma concentration of phytoestrogens in Japanese men. Lancet 342: 1209-1210.

Agnusdei D, Bufalino L (1997) Efficacy of ipriflavone in established osteoporosis and long-term safety. Calcif Tissue Int 61 (Suppl 1): S23-S27.

Akiyama T, Ishida J, Nakagawa S, Ogawara H, Watanabe S, Itoh N, Shibuya M, Fukami Y (1987) Genistein, a specific inhibitor of tyrosine-specific protein kinases. I Biol Chem 262: 5592-5595.

Al-Maharik N, Botting NP (2006) A facile synthesis of isoflavone 7-Oglucuronides. Tetrahedron Lett 47: 8703-8706.

Banerjee S, Li Y, Wang Z, Sarkar FH (2008) Multi-targeted therapy of cancer by genistein. Cancer Lett 269: 226-242.

Barbieri M (2008) The code model of semiosis: the first steps toward a scientific biosemiotics. Am J Semiot 2008: 23-37.

Birt DF, Hendrich S, Wang W (2001) Dietary agents in cancer prevention: flavonoids and isoflavonoids. Pharmacol Ther 90: 157-177.

Bonrath W (2004) Chemical reactions under „,non-classical conditions”, microwaves and ultrasound in the synthesis of vitamins. Ultrason Sonochem 11: 1-4. 
Booth C, Hargreaves DF, Hadfield JA, McGown AT, Potten CS (1999) Isoflavones inhibit intestinal epithelial cell proliferation and induce apoptosis in vitro. Br J Cancer 80: 1550-1557.

Boryski J, Grynkiewicz G (2001) A regioselective synthesis of genistein 4'-O-ribofuranosides. Synthesis 2001: 2170-2174.

Buer CS, Muday GK, Djordjevic MA (2007) Flavonoids are differentially taken up and transported long distances in Arabidopsis Plant Physiol 145: 478-490.

Chan JM, Gann PH, Giovannucci EL (2005) Role of diet in prostate cancer development and progression. J Clin Oncol 23: 8152-8160.

Clunes MT, Boucher RC (2008) Front-runners for pharmacotherapeutic correction of the airway ion transport defect in cystic fibrosis. Curr Opin Pharmacol 8: 292-299.

Coldham NG, Sauer MJ (2000) Pharmacokinetiks of $\left[{ }^{14} \mathrm{C}\right]$ genistein in the rat: gender-related differences, potential mechanism of biological action, and implications for human health. Toxicol Appl Pharmacol 164: 206-215.

Cowan MM (1999) Plant products as antimicrobial agents. Clin Microbiol Rev 12: 564-582.

Davis DD, Diaz-Cruz ES, Landini S, Kim YW, Brueggemeier RW (2008) Evaluation of synthetic isoflavones on cell proliferation, estrogen receptor binding affinity, and apoptosis in human breast cancer cells. J Steroid Biochem Mol Biol 108: 23-31.

Dewick PM (2009) Medicinal natural products: a biosynthetic approach, Dewick PM ed, pp 7-34; 121-157. Wiley \& Sons, Chichester, UK.

Dixon RA (1999) Isoflavonoids: biochemistry, molecular biology and biological functions. In: Comprehensive Natural Products Chemistry. Sankawa U ed, 1: 773-823. Elsevier, Amsterdam.

Dixon RA, Ferreira D (2002) Genistein. Phytochem 60: 205-211.

Ek O, Yanishevski Y, Zeren T, Waurzyniak B, Gunther R, Chelstrom L, Chandan-Langlie M, Schneider E, Myers DE, Evans W, Uckun FM (1998) In vivo toxicity and pharmacokinetic features of B43(antiCD19)-genistein immunoconjugate. Leuk Lymphoma 30: 389-394.

Ferrier RJ, Zubkov OA (2003) Transformation of glycals into 2,3-unsaturated glycosyl derivatives. Org Reactions 62: 569-736.

Eustache F, Mondon F, Canivenc-Lavier MC, Lesaffre C, Fulla Y, Berges R, Cravedi JP, Vaiman D, Auger J, Chan WH (2009) Chronic dietary exposure to a low-dose mixture of genistein and vinclozolin modifies the reproductive axis, testis transcriptome, and fertility. Environ Health Perspect 117: 1272-1279.

Galietta LJV, Springsteel MF, Eda M, Niedzinski EJ, By K, Haddadin MJ, Kurth MJ, Nantz MH, Verkman AS (2001) Novel CFTR chloride channel activators identified by screening of combinatorial libraries based on flavone and benzoquinolizinium lead compounds. J Biol Chem 276: 19723-19728.

Gargala, G, Baishanbo A, Favennec L, Francois A, Ballet JJ, Rossignol JF (2005) Inhibitory activities of epidermal growth factor receptor tyrosine kinase-targeted dihydroxyisoflavone and trihydroxydeoxybenzoin derivatives on Sarcocystis neurona, Neospora caninum, and Cryptosporidium parvum development. Antimicrob Agents Chemother 49: 4628-4634.

Grynkiewicz G, Ksycińska H, Ramza J, Zagrodzka J (2005) Chromatographic quantification of isoflavones (why and how). Acta Chromatogr 15: $31-65$.

Grynkiewicz G, Szeja W, Boryski J (2008) Synthetic analogs of natural glycosides in drug discovery and development. Acta Pol Pharm 65: 655-676.

Grynkiewicz G, Zegrocka-Stendel O, Pucko W, Ramza J, Kościelecka A, Kołodziejski W, Woźniak K (2004) X-ray and ${ }^{13} \mathrm{C}$ CP MAS investigation of structure of two genistein derivatives. J Mol Struct 694: $121-129$.

Grynkiewicz G (2002) Synthetic genistein as a prospective active ingredient for nutrition and medicine. Pol J Food Nutr Sci 11/52 (SI 2): 99-105.

Guilet R, Berlan J, Louisnard O, Shwartzentruber J (1998) Influence of ultrasound power on the alkylation of phenylacetonitrile under solid-liquid phase transfer catalysis conditions. Ultrason Sonochem 5: 21-25.

He Y, Chen LL, Zhang ZT (2008) Synthesis of 7,4'-bis-(hydroxyl)$8,3^{\prime}, 5^{\prime}$-tris-(hydroxymethyl)isoflavone and crystal structure of its ester. J Chem Crystallogr 38: 27-31.

Heemstra JM, Kerrigan SA, Doerge DR, Helferich WH, Boulanger WA (2006) Total synthesis of (S)-equol. Org Lett 8: 5441-5443.

Hofmann J, Freier U, Wecks M (2003) Ultrasound promoted C-alkylation of benzyl cyanide - effect of reactor and ultrasound parameters. Ultrason Sonochem 10: 271-275.

Holzbeierlein JM, Mcintosh J, Thrasher JB (2005) The role of soy phytoestrogens in prostate cancer. Curr Opin Urol 15: 17-22.

Hong H, Landauer MR, Foriska MA, Ledney GD (2006) Antibacterial activity of the soy isoflavone genistein. I Basic Microbiol 46: 329-335.

Hukkanen M, Platts LA, Lawes T, Girgis SI, Konttinen YT, Goodship AE (2003) Effect of nitric oxide donor hitroglycerin on bone mineral density in a rat model of estrogen deficiency-induced osteopenia. Bone 32: 142-149.

Hussain M, Sarkar F, Djuric Z (2002) Soy isoflavones in the treatment of prostate cancer. $J$ Nutr 132: 575S-576S.
Iriti M, Faoro F (2009) Chemical diversity and defence metabolism: how plants cope with patogens and ozone pollution. Int J Mol Sci 10: 3371-3399.

Jakóbkiewicz-Banecka J, Piotrowska E, Narajczyk M, Barańska S, Węgrzyn G (2009) Genistein-mediated inhibition of glycosaminoglycan synthesis, which corrects storage in cells of patients suffering from mucopolysaccharidoses, acts by influencing an epidermal growth factor-dependent pathway. J Biomed Sci 16: 26.

Jefferson WN, Padilla-Banks E, Newbold RR (2007) Disruption of the female reproductive system by the phytoestrogen genistein. Reprod Toxicol 23: 308-316.

Kim YW, Mobley JA, Bruegemeier RW (2003) Synthesis and estrogen receptor binding activities of 7-hydroxy-3-(4-hydroxyphenyl)-4H-1benzopyran-4-ones containing a basic side chain. Bioorg Med Chem Lett 13: 1475-1478.

Klinge C (2000) Estrogen receptor interaction with co-activators and co-repressors. Steroids 65: 227-251.

Kloska A, Piotrowska E, Jakóbkiewicz-Banecka J, Tylki-Szymańska A, Czartoryska B, Węgrzyn G (2006) Effect of genistein synthetic derivatives on regulation of glycosaminoglycan synthesis in Sanfolippo disease (mucopolysaccharidosis type III). Conference Abstract, V Multidyscyplinarna Konferencja Nauki o Leku, on-line journal.

Kohen F, Gayer B, Amir-Zaltsman Y, Ben-Hur H, Thomas E, Lu LJ (1999) A nonisotopic enzyme-based immunoassay for assessing human exposure to genistein. Nutr Cancer 35: 96-103.

Kohen F, Gayer B, Kulik T, Frydman V, Nevo N, Katzburg S, Limor R, Sharon O, Stern N, Somjen D (2007) Synthesis and evaluation of the antiproliferative activities of derivatives of carboxyalkyl isoflavones linked to N-t-Boc-hexylenediamine. J Med Chem 50: 64056410 .

Kostelac D, Rechkemmen G, Briviba K (2003) Phytoestrogens modulate binding response of estrogen receptors $\alpha$ and $\beta$ to the estrogen response element. J Agric Food Chem 51: 7632-7635.

Ksycińska H, Sobik B, Popiołkiewicz J, Polkowski K, Krzeczyński P, Ramza J, Pucko W, Grynkiewicz G (2004) Determination of new derivatives of genistein in culture media by liquid chromatography. $J$ Chromatogr B, 799: 217-231.

Kuiper GG, Lemmen JG, Carlsson B, Gorton JC, Safe SH, van der Saag PT, van der Burg B, Gustafsson JA (1998) Interaction of estrogenic chemicals and phytoestrogens with estrogen receptor $\beta$. Endocrinology 139: 4252-4263.

Kurzer MS (2002) Hormonal effects of soy in premenopausal women and men. J Nutr 132: 570S-573S.

Leopold AS, Erwin M, Oh J (1976) Phytoestrogens: adverse effects on reproduction in Califormnia quail. Science 191: 98-100.

Lewis P T, Wähälä K, Hoikkala A, Mutikainen I, Meng QH, Adlercreutz H, Tikkanen MJ (2000) Synthesis of antioxidant isoflavone fatty acid esters. Tetrabedron 56: 7805-7810.

Lewis P, Kaltia S, Wähälä K (1998) The phase transfer catalysed synthesis of isoflavone-O-glucosides. J Chem Soc Perkin Trans 1: 24812484

Lewis PT, Wähälä K (1998) Regiospecific 4'-O- $\beta$-glucosidation of isoflavones. Tetrabedron Lett 39: 9559-9562.

Li HQ, Ge HM, Chen YX, Xu C, Shi L, Ding H, Zhu HL (2006) Synthesis and cytotoxic evaluation of a series of genistein derivatives. Chem Biodivers 3: 463-472.

Li HQ, Xue JY, Shi L, Gui SY, Zhu HL (2008) Synthesis, crystal structure and antimicrobial activity of deoxybenzoin derivatives from genistein. Eur J Med Chem 43: 662-667.

Li JT, Yang WZ, Wang SX, Li SH, Li TS (2002) Improved synthesis of chalcones under ultrasound irradiation. Ultrason Sonochem 9: 237-239.

Magee PJ, Rowland IR (2004) Phyto-estrogens, their mechanism of action: current evidence for role in breast and prostate cancer. $\mathrm{Br} J$ Nutr 91: 513-531.

Malinowska M, Wilkinson FL, Bennett W, Langford-Smith KJ, O'Leary HA, Jakobkiewicz-Banecka J, Wynn R, Wraith JE, Wegrzyn G, Bigger WB (2009) Genistein reduces lysosomal storage in peripheral tissues of mucopolysaccharide IIIB mice. Mol Gen Metabol 98: 235-242.

Manash KP, Mukhopadhyay AK (2004) Tyrosine kinase - role and significance in cancer. Int J Med Sci 1: 101-115.

Markovits J, Linassier C, Fosse P, Couprie J, Pierre J, Jacquemin-Sablon A, Saucier JM, Le Pecq JB, Larsen AK (1989) Inhibitory effects of the tyrosine kinase inhibitor genistein on mammalian DNA topoisomerase II. Cancer Res 49: 5111-5117.

Matsukawa Y, Marui N, Sakai T, Satomi Y, Yoshida M, Matsumoto K, Nishino H, Aoike A (1993) Genistein arrest cell cycle progression at G2/M. Cancer Res 53: 1328-1331.

Matsumoto T, Kobayashi T, Kikuchi T, Honda T, Kamata K (2005) Effects of dual-action of genistein derivatives on relaxation in rat aorta. J Smooth Muscle Res 41: 23-33.

Mazurek AP, Kozerski L, Sadlej J, Kawęcki R, Bednarek E, Sitkowsk J, Dobrowolski J-Cz, Marin JK, Biniecki K, Witowska J, Fiedor P, Pachecka J (1998) Genistein complexes with amines: structure and properties. J Chem Soc Perkin Trans 2: 1223-1230. 
Meeran SM, Katiyai KS (2008) Cell cycle control as a basis for cancer chemoprevention through dietary agents. Front Biosci 13: 2191-2202.

Meng QH, Lewis P, Wähälä K, Adlercreutz H, Tikkanen MJ (1999a) Incorporation of esterified soybean isoflavones with antioxidant activity into low density lipoprotein. Biochim Biophys Acta 1438: 369376.

Meng QH, Wähälä K, Adlercreutz H, Tikkanen MJ (1999b) Antiproliferative efficacy of lipophilic soy isoflavone phytoestrogens delivered by low density lipoprotein particles into cultured U937 cells. Life Sci 65: 1695-1705.

Messinger Y, Yanishevski Y, Ek O, Zeren T, Waurzyniak B, Gunther R, Chelstrom L, Chandan-Langlie M, Schneider E, Myers DE, Evans W, Uckun FM (1998) In vivo toxicity and pharmacokinetic features of B43 (anti-CD19)-genistein immunoconjugate in nonhuman primates. Clin Cancer Res 4: 165-170.

Miller MR, Megson IL (2007) Recent developments in nitric oxide donor drugs. Br J Pharmacol 151: 305-321.

Morton MS, Chan PS, Cheng C, Blacklock N, Matos-Ferreira A, Abranches-Monteiro L, Correia R, Lloyd S, Griffiths K (1997) Lignans and isoflavonoids in plasma and prostatic fluid in men: samples from Portugal, Hong Kong, and the United Kingdom. Prostate 32: 122-128.

Musialik M, Kuzmicz R, Pawłowski TS, Litwinienko G (2009) Acidity of hydroxyl groups: an overlooked influence on antiradical properties of flavonoids. J Org Chem 74: 2699-2709.

Naguleswaran A, Spicher M, Vonlaufen N, Ortega-Mora LM., Torgerson P, Gottstein B, Hemphill A (2006) In vitro metacestodicidal activities of genistein and other isoflavones against Echinococcus multilocularis and Echinococcus granulosus. Antimicrob Agents Chemother 50: 3770-3778.

Nishiyama K, Esaki S, Deguchi I, Sugiyama N, Kamiya S (1993) Syntheses of isoflavones and isoflavone glycosides, and their inhibitory activity against bovine liver $\beta$-galactosidase. Biosci Biotech Biochem 57: 107-114.

Noguchi A, Saito A, Homma Y, Nakao M, Sasaki N, Nishino T, Takahshi S, Nakayama T (2007) A UDP-glucose:isoflavone 7-O-glucosyltransferase from the roots of soybean (Glycine max) seedlings. I Biol Chem 282: 23581-23590.

Offen W, Martinez-Fleites C, Yang M, Kiat-Lim E, Davis BG, Tarling CA, Ford CM, Bowles DJ, Davies GJ (2006) Structure of a flavonoid glucosyltransferase reveals the basis for plant natural product modification. EMBO J 25: 1396-1405.

Ogawara H, Akiyama T, Watanabe S, Ito N, Kobori M, Seoda Y (1989) Inhibition of tyrosine protein kinase activity by synthetic isoflavones and flavones. J Antibiot 42: 340-343.

Oldfield MF, Chen L, Botting NP (2007) The synthesis of $\left[3,4,1^{1}-{ }^{13} \mathrm{C}_{3}\right]$ genistein. I Label Comp Radiopharm 50: 1266-1271.

Peer WA, Murphy AS (2008) Flavonoids as signal molecules: targets of flavonoid action. In: The science of flavonoids. Grotewold E. ed pp 239-268. Springer, New York, NY.

Pelter A, Ward RS, Whalley JL (1998) A facile synthesis of 2-substituted isoflavones for immunoassay: assembly of the isoflavonoid skeleton by means of a novel cyclization reaction. Synthesis 12: 1793-1802.

Pelter A, Ward RS, Whalley JL (1999) The synthesis of 2-substituted isoflavones for immunoassay. Envir Tox Pharmacol 7: 217-220.

Pike ACW, Brzozowski AM, Hubbard RE, Bonn T, Thorsell A-G, Engstrom O, Ljunggren J, Gustafsson J-L, Carlquist M (1999) Structure of the ligand binding domain of estrogen receptor beta in the presence of a partial agonist and a full antagonist. EMBO J 18: $4608-4618$.

Piotrowska E, Jakóbkiewicz-Banecka J, Baranska S, Tylki-Szymańska A, Czartoryska B, Węgrzyn A, Węgrzyn G (2006) Genistein-mediated inhibition of glycosaminoglycan synthesis as a basis for gene expression-targeted isoflavone therapy for mucopolysaccharidoses. Eur J Human Gen 14: 846-852.

Piotrowska E, Jakóbkiewicz-Banecka J, Tylki-Szymańska A, Liberek A, Maryniak A, Malinowska M, Czartoryska B, Puk E, Kloska A, Liberek T, Barańska S, Węgrzyn A, Węgrzyn G (2008) Genistein-rich soy isoflavone extract in substrate reduction therapy for Sanfilippo syndrome: an open-label, pilot study in 10 pediatric patients. Curr Therap Res 69: 166-179.

Piotrowska E, Jakóbkiewicz-Banecka J, Węgrzyn G (2009) Different amounts of isoflavones in various commercially available soy extracts in the light of gene expression-targeted isoflavone therapy. Phytother Res 24: S109-S113.

Polkowski K, Popiołkiewicz J, Krzeczyński P, Ramza J, Pucko W, Zegrocka-Stendel O, Boryski J, Skierski JS, Mazurek AP, Grynkiewicz $\mathrm{G}$ (2004) Cytostatic and cytotoxic activity of synthetic genistein glycosides against human cancer cell lines. Cancer Lett 203: 59-69.

Polkowski K, Skierski JS, Mazurek AP (2000) Anticancer activity of genistein-piperazine complex. In vitro study with HL-60 cells. Acta Pol Pharm - Drug Res 57: 223-231.

Popiołkiewicz J, Polkowski K, Skierski JS, Mazurek AP (2005) In vitro toxicity evaluation in the development of new anticancer drugs genistein glycosides. Cancer Lett 229: 67-75.
Prasain JK, Wang CC, Barnes S (2004) Mass spectrometric methods for the determination of flavonoids in biological samples. Free Rad Biol Med 37: 1324-1356.

Reuben S, Cseke LJ, Bhinu VS, Narasimhan K, Jeyakumar M, Swaru S (2005) Molecular Biology of Plant Natural Products. In Natural products; drug discovery and therapeutic medicine. Zhang L, Demain AL, eds, pp 165-202. The Humana Press, Totowa, NJ.

Rusin A, Gogler A, Głowala-Kosińska M, Bochenek D, Gruca A Grynkiewicz G, Zawisza J, Szeja W, Krawczyk Z (2009) Unsaturated genistein disaccharide glycoside as a novel agent affecting microtubules. Bioorg Med Chem Lett 19: 4939-4943.

Sakai T, Kogiso M (2008) Soy isoflavones and immunity. J Med Invest 55: $167-173$

Sarkar FH, Adsule S, Padhye S, Kulkarni S, Li Y (2006) The role of genistein and synthetic derivatives of isoflavone in cancer prevention and therapy. Mini-Rev Med Chem 6: 401-407.

Setchell KDR (2001) Soy isoflavones-benefits and risks from nature's selective estrogen receptor modulators (SERMs). J Amer College Nutr 20: 354S-362S.

Setchell KDR, Brown NM, Lydeking-Olsen E (2002) The clinical importance of the metabolite equol - a clue to the effectiveness of soy and its isoflavones. J Nutr 132: 3577-3584.

Shchemelinin I, Sefc L, Necas E (2006) Protein kinases, their function and implication in cancer and other diseases. Fol Biol (Praha) 52: $81-101$.

Silasi DA, Alvero AB, Rutherford TJ, Brown D, Mor G (2009) Phenoxodiol: pharmacology and clinical experience in cancer monotherapy and in combination with chemotherapeutic drugs. Expert Opin Pharmacother 10: 1059-1067.

Shelnutt SR, Cimino CO, Wiggins PA, Ronis MJJ, Badger TM (2002) Pharmacokinetics of the glucuronide and sulfate conjugates of genistein and daidzein in men and women after consumption of a soy beverage. Amer J Clin Nutr 76: 588-594.

Simons AL, Renouf M, Murphy PA, Hendrich S (2010) Greater apparent absorption of flavonoids is associated with lesser human fecal flavonoid disappearance rates. J Agric Food Chem 58: 141-147.

Soidinsalo O, Wähälä K (2004) Synthesis of phytoestrogenic isoflavonoid disulphates. Steroids 69: 613-616.

Somjen D, Amir-Zaltsman Y, Gayer B, Kulik T, Knoll E, Stern N, Lu LJ, Toldo L, Kohen F (2002) 6-Carboxymethyl genistein: a novel selective oestrogen receptor modulator (SERM) with unique, differential effects on the vasculature, bone and uterus. J Endocrinol 173: 415-427.

Somjen D, Stern N, Knoll E, Sharon O, Gayer B, Kulik T (2003) Carboxy derivatives of isoflavones as affinity carriers for cytotoxic drug targeting in adrenocortical H295R carcinoma cells. J Endocrinol 179: 395-403.

Sonn GA, Aronson W, Litwin MS (2005) Impact of diet on prostate cancer: a review. Prostate Cancer Prostatic Dis 8: 304-310.

Squadrito F, Bitto A, Marini H, D’Anna R, Altavilla D (2009) Genistein aglycone effectively manages postmenopausal bone loss. J Clin Densit 12: 396-396.

Środa K, Michalak K, Maniewska J, Grynkiewicz G, Szeja W, Zawisza $\mathrm{J}$, Hendrich AB (2008) Genistein derivatives decerease liposome membrane integrity - calcein release and molecular modelling study. Biophys Chem 138: 78-82.

Stachulski AV, Berry NG, Low ACL, Moores SL, Row E, Warhurst DC, Adagu IS, Rossignol JF (2006) Identification of isoflavone derivatives as effective anticryptosporidial agents in vitro and in vivo. $J$ Med Chem 49: 1450-1454.

Szeja W, Pastuch G, Wandzik I, Kuźnik N, Grynkiewicz G (2003) Synthesis of selectively protected genistein derivatives. Synth Commun 33: 4107-4117.

Uckun FM, Messinger Y, Chen CL, O’Neill K, Myers DE, Goldman F, Hurvitz C, Casper JT, Levine A (1999) Treatment of therapy-refractory B-lineage acute lymphoblastic leukemia with an apoptosisinducing CD19-directed tyrosine kinase inhibitor. Clin Cancer Res 5: 3906-3913.

Uckun FM, Narla RK, Zeren T, Yanishevski Y, Myers DE, Waurzyniak B, Ek O, Schneider E, Messinger Y, Chelstrom LM, Gunther $\mathrm{R}$, Evans W (1998) In vivo toxicity, pharmacokinetics, and anticancer activity of Genistein linked to recombinant human epidermal growth factor. Clin Cancer Res 4: 1125-1134.

Ulanowska K, Majchrzak A, Moskot M, Jakóbkiewicz-Banecka J, Węgrzyn G (2007) Assessment of antibacterial effects of flavonoids by estimation of generation times in liquid bacterial cultures. Biologia Bratisl) Sec Cell Mol Biol 62: 132-135.

Ulanowska K, Tkaczyk A, Konopa G, Węgrzyn G (2006) Differential antibacterial activity of genistein arising from global inhibition of DNA, RNA and protein synthesis in some bacterial strains. Arch Microbiol 184: 271-278.

Ullmann U, Bendik I, Flühmann B (2005) Bonistein (synthetic genistein) a food component in development for a bone health nutraceutical. J Physiol Pharmacol 56 (Suppl 1): 79-95.

Veitch NC (2007) Isoflavonoids of the leguminosae. Nat Prod Rep 24: 417-464. 
Verdrengh M, Collins LV, Bergin P, Tarkowski A (2004) Phytoestrogen genistein as an anti-staphylococcal agent. Microbes Infect 6: 86-92.

Wähälä K, Rasku S (1997) Synthesis of $\mathrm{D}_{4}$-genistein, a stable deuteron labeled isoflavone by a predeuteration-selective dedeuteration approach. Tetrahedron Lett 38: 7287-7290.

Wang J, Shang F, Jing R, Liu L, Wang S, Hou J, Huan M, Mei Q (2007) Nitric oxide-donating genistein prodrug: design, synthesis and bioactivity of MC3T3-E1 cells. J Pharmacol Sci 104: 82-89.

Wang SF, Jiang Q, Ye YH, Li Y, Tan RX (2005) Genistein derivatives as selective estrogen receptor modulators: Sonochemical synthesis and in vivo anti-osteoporotic action. Bioorg Med Biochem 13: 4880-4890.

Wang SF, Ye YH, Zhang Z, Tan RX (2006) Regioselective sonochemical synthesis of genistein derivatives. Ultrason Sonochem 13: 28-31.

Węgrzyn G, Jakóbkiewicz-Banecka J, Gabig-Cimińska M, Piotrowska E, Narajczyk M, Kloska A, Malinowska M, Dziedzic D, Gołębiewska I, Moskot M, Węgrzyn A (2009) Genistein: a natural isoflavone with a potential for treatment of genetic diseases. Biochem Soc Trans in press.

Whalley JL, Oldfield MF, Botting NP (2000) Synthesis of $\left[4-{ }^{13} \mathrm{C}\right]$-isoflavonoid phytoestrogens. Tetrabedron 56: 455-460.

Wimalawansa SJ (2000) Nitroglycerin therapy is as efficatious as standard estrogen replacement therapy (Premarin) in prevention of oophorectomy-induced bone loss: a human pilot clinical study. $J$ Bone Miner Res 15: 2240-2244.
Wiseman H (2006) Isoflavonoids and human health. In Flavonoids, chemistry, biochemistry and applications. Anderson OM, Markham KR, eds, pp 371-396. CRC Press, Boca Raton, FL.

Ye R, Bodero A, Zhou BB, Khamma KK, Lavin MF, Lees-Miller SP (2001) The plant isoflavonoid genistein activates p53 and Chk2 in an ATM-dependent manner. J Biol Chem 276: 4828-4833.

Yuan L, Wagatsuma C, Sun B, Kim JH, Surh YJ (2003) The role of beta-glucuronidase in induction of apoptosis by genistein combined polysaccharide in xenogeneic mice bearing human mammary cancer cells. Ann N Y Acad Sci USA 1010: 347-349.

Zemplen G, Farkas L (1943) Synthesis of genistin. Ber Dtsch Chem Ges 76B: $1110-1112$.

Zhang LN, Cao P, Tan SH, Gu W, Shi L, Zhu HL (2008) Synthesis and antimicrobial activities of 7-O-modified genistein derivatives. Eur J Med Chem 43: 1543-1551.

Zhang LN, Xiao ZP, Ding H, Ge HM, Xu C, Zhu HL, Tan RX (2007) Synthesis and cytotoxic evaluation of novel 7-O-modified genistein derivatives. Chem Biodivers 4: 248-255.

Zielonka J, Gębicki J, Grynkiewicz G (2003) Radical scavenging properties of genistein. Free Rad Biol Med 35: 958-965.

Zierau O, Kolba S, Olff S, Vollmer G, Diel P (2006) Analysis of the promoter-specific estrogenic potency of the phytoestrogens genistein, daidzein, and coumestrol. Planta Med 72: 184-186. 